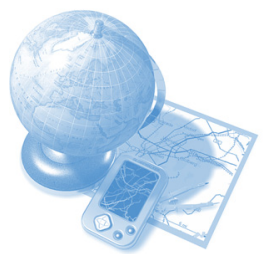

Tina Overton*

and

Nicholas Potter

Department of Chemistry

University of Hull

Hull HU6 7RX

*t.I.overton@hull.ac.uk

n.m.potter@hull.ac.uk
The resource was designed with built-in flexibility so that each section could be used individually to supplement other areas of the chemistry curriculum.

\section{Context based learning in chemistry: Chemistry in Sport}

\author{
Abstract \\ A learning resource for part-time 1st year foundation degree students was designed to \\ be completed entirely by independent study. The course presented chemistry in the \\ context of sport and investigated the use of a number of alternative methods of teaching/ \\ learning, including: \\ - The Perry Scheme of Intellectual Development \\ - Multiple intelligences (MI) Theory \\ - Problem-Based Learning (PBL) \\ - Context Based Learning (CBL) \\ - Mind Mapping \\ - $\quad$ Case Studies \\ - Web-based independent learning
}

A website containing questions, hyperlinks to further content and external webpages was produced.

The students' response was positive. They enjoyed the course, found the context interesting and the presentation helpful. The assessment marks improved (a 5-6\% increase) compared to a more traditional paper based course. As only eight students took the course these results cannot be seen as statistically significant but provide a good indication that this was an effective approach.

In completing their assessments and pre and post questionnaires the students provided valuable feedback that will enable improvements to the learning resource.

\section{Introduction}

The use of a real life context to teach chemistry has been shown to enhance levels of student engagement and enthusiasm for learning ${ }^{1-4}$. Margetson ${ }^{5}$ stresses the value of knowledge and skills acquired in context. Coles ${ }^{6}$ reports that students who see the interconnections and links between different knowledge areas gain the highest scores in examinations which tested that knowledge and were more able to retrieve and use the information they had learnt. Coles sees context as essential for elaborated learning. For elaborated learning to occur students must be given the opportunity to relate what they now need to know to past experiences and prior knowledge. Within a context, Coles says, students will be able to better see their task as "linking together aspects of knowledge both within and between subjects, and relating what they are learning now to what they already know". Coles concludes that "elaboration is unlikely to occur under the conventional curriculum arrangement, and does not necessarily occur during problembased learning". He proposes a more general model of education called contextual learning, suggesting that elaboration can occur if students have: an appropriate context for learning; information or access to information potentially relatable to that context and opportunities to handle the information in order to make connections. In cases where students are given an appropriate context they report 'things coming together'. Rogers ${ }^{7}$ says context provides a motivating force for the student through which the student develops a wish to know more and wants rather than needs to learn.

In arguing the case for teaching chemistry in context Hills ${ }^{8}$ identifies the fact that most current scientific knowledge is explicit ie factual precise data. Implicit knowledge is personal, emotional, not yet defined and not scientific. This implicit knowledge is generally ignored in science and students are only examined on their explicit knowledge. Hills argues that this depersonalisation removes much of the interest in scientists and in science itself. 
Context-based learning resources can be presented as problem solving case studies. According to Belt and Phipps ${ }^{1}$ case studies can be used to address a range of skills, develop a mode of thinking, working and communicating, and are best done by tackling open-ended problems. Overton ${ }^{3}$ states that students undertaking problem- and context-based courses show that there are many benefits to be gained from this approach. Students' motivation, attitude to study, long-term retention of knowledge, use of resources, key skills and success as postgraduates are all significantly superior when compared to students taught by conventional methods.

Although many learning resources are made available via the web, a limited amount of research has been carried out on its effectiveness as a learning tool.

Arasasingham et $\mathrm{al}^{8}$ assessed large numbers of students on their understanding of stoichiometry using a web-based assessment program. With a group of students using textbooks and paper to complete the assessments as the control group, they were able to compare the web- and non-webbased approaches. The assessment results found that the web-based students outperformed the non-web-based students and showed greater conceptual understanding. The students using the webbased course also reported that having to work independently with the program forced them to work harder on the subject with the pay offs being instant feedback and greater understanding.

We aimed to use the benefits of context based learning presented as a case study on the chemistry of sport with the advantages of using the web for independent study.

\section{Chemistry in Sport}

The learning resource developed was a case study on the applications of chemistry in sport. The target students were part-time chemistry undergraduates without timetabled support for the module and with limited access to the library, so the teaching method had to be tailored to an independent learning approach. The resource provided the students with content and they were given tasks throughout. The tasks were designed to enhance understanding and extend the content already presented. Many of the tasks were open ended without a definite right or wrong answer, and the students had to support and defend their answers.

As sport pervades modern popular culture, it was decided to use the applications of chemistry in sport as the context. Interest in the context would be a 'way in' to the subject matter, prompting a motivation to learn on the part of the students.
The learning resource comprised three sections. The first looked at the use of performance-enhancing drugs from the point of view of detection and was, therefore, primarily concerned with analytical chemistry. The students were asked to look at the cases of three British athletes who had recently been involved in drug scandals. In recent years, the methods employed to detect performance-enhancing drugs, and the validity of those methods, have courted as much controversy as the cases themselves. Each case had called into question the techniques of detection, and highlighted the problems involved in the detection of performance enhancing drugs.

The second section focused on the three energy systems present within muscle cells and was, therefore, primarily concerned with biochemistry, focusing on the biochemical precursors to muscle movement and the ways in which athletes legally supplement these.

The final section investigated sporting equipment and materials chemistry. Carbon fibre and Kevlar were identified as materials frequently used in sporting equipment, and the production, structure and application of these materials was investigated.

The resource was designed with built-in flexibility so that each section could be used individually to supplement other areas of the chemistry curriculum.

\section{Presentation}

The overall structure of the course was visualised using a mind mapping software called Inspiration (ver 7.5 Intl.). As well as text, the software could display pictures, diagrams and links between ideas and concepts. The Inspiration software was capable of producing an HTML document from the collection of hyperlinked mind maps. This enabled us to present the resource as a website, and content could then be linked to external websites containing relevant information for background and further reading, putting the content further into context and informing the students' learning.

The Olympic motto is "citius, altius, fortius" (faster, higher, stronger) The introductory page of the learning resource posed the question: "what makes our sports stars faster, higher, stronger?" (see Figure 1). A screenshot of the introductory page is shown in Figure 2. A summary of the learning resource content and tasks can be found in Table 1. 